\title{
Correction to: Factors predicting long-term comorbidities in patients with Cushing's syndrome in remission
}

\author{
Marie Helene Schernthaner-Reiter ${ }^{1} \cdot$ Christina Siess $^{1} \cdot$ Alois Gessl $^{1} \cdot$ Christian Scheuba $^{2} \cdot$ Stefan Wolfsberger $^{3}$. \\ Philipp Riss ${ }^{2} \cdot$ Engelbert Knosp $^{3} \cdot$ Anton Luger $^{1} \cdot$ Greisa Vila $^{1}$
}

Published online: 24 January 2019

(c) The Author(s) 2019

\section{Correction to: Endocrine}

https://doi.org/10.1007/s12020-018-1819-6;

The original version of this article unfortunately published with traditional Springer copyright instead of open access under Springer compact agreement.

The copyright line, the license statement and the funding acknowledgement section are missing in the original publication. These information are given below.

The original article has been corrected.

Acknowledgements
Open access funding provided by the Medical University of Vienna.

Open Access: This article is distributed under the terms of the Creative Commons Attribution 4.0 International License (http://creativecommons.org/licenses/by/4.0/), which permits use, duplication, adaptation, distribution, and reproduction in any medium or format, as long as you give appropriate credit to the original author(s) and the source, provide a link to the Creative Commons license, and indicate if changes were made.

The original article can be found online at https://doi.org/10.1007/ s12020-018-1819-6.

$\triangle$ Greisa Vila

greisa.vila@meduniwien.ac.at

1 Clinical Division of Endocrinology and Metabolism, Department of Internal Medicine III, Medical University of Vienna,

Vienna, Austria

2 Department of Surgery, Medical University of Vienna, Vienna, Austria

3 Department of Neurosurgery, Medical University of Vienna, Vienna, Austria 